\title{
Highly efficient Pd-Fe/Ni foam as heterogeneous Fenton catalysts for the three-dimensional electrode system
}

Yuxin Liu, Zebin Yu*, Yanping Hou, Zhenbo Peng, Li Wang, Zhuqing Gong, Jie Zhu, Dandan $\mathrm{Su}$

School of Environment, Guangxi University, Nanning 530004, P.R. China

\begin{abstract}
A novel particle electrode (PE) Pd-Fe/Ni foam was synthesized and used for Dimetridazole (DMZ) degradation in the three-dimensional electrode (3D) system. Results showed that $\mathrm{Pd}-\mathrm{Fe} / \mathrm{Ni}$ foam exhibited excellent electrocatalytic activity and satisfactory electrocatalytic stability. Inducing Pd and Fe species could not only decrease the resistance and accelerate the electron transfer, but also cause synergistic effect. In the 3D system with $\mathrm{Pd}-\mathrm{Fe} / \mathrm{Ni}$ foam PEs, DMZ degradation was much more efficient as compared with those using $\mathrm{Ni}$ foam PEs, Fe/Ni foam PEs and Pd/Ni foam PEs, owing to direct electrolysis, and efficient production of $\mathrm{H}_{2} \mathrm{O}_{2}$ and $\cdot \mathrm{OH}$ of Pd-Fe/Ni foam PEs.
\end{abstract}

Keywords: Three-dimensional system, Pd-Fe/Ni foam, Heterogeneous Fenton catalyst, Synergistic effect

\section{Introduction}

The three-dimensional (3D) electrode has been attracting much attention recently

Corresponding author. Tel./fax.: + 8607713270672

E-mail: xxzx7514@hotmail.com(Z.Yu) 
since by placing a large number of particle electrodes (PEs) into the 3D reactor, charged microelectrodes could be formed and resulting in much larger interfacial electrode surface area and higher mass-transfer efficiency as compared to conventional two-dimensional (2D) electrodes [1]. The properties of PEs are crucial for the entire system, and activated carbon, metal particles, carbon aerogels and $\mathrm{Ni}$ foam are commonly used as PEs [2-5]. Among them, Ni foam has been widely used as a promising PEs due to its good electrical conductivity, well-developed porous structure and high catalytic activity [6]. Liu et al. [5] reported that Ni foam as PEs displayed good oxygen reduction activity in 3D electrode system, because it could activate molecular oxygen to generate $\cdot \mathrm{O}_{2}^{-}$via a single-electron transfer pathway and subsequently generated $\mathrm{H}_{2} \mathrm{O}_{2}$, and afterwards, $\cdot \mathrm{OH}$ was produced in the presence of $\mathrm{Fe}(\mathrm{II})$ (Eqs. (1) - (3)). However, the amount of $\mathrm{H}_{2} \mathrm{O}_{2}$ generated by $\mathrm{Ni}$ foam was limited. In this case, to achieve high efficiency, efficient carbonaceous materials should be employed as the cathode, and besides, $\mathrm{Fe}^{2+}$ should be added to the system to catalyze $\cdot \mathrm{OH}$ production. Nevertheless, carbonaceous materials are costly and their mechanical stability is low; also, $\mathrm{Fe}^{2+}$ addition makes the process more complicated; which limited this kind of system for practical application.

$$
\begin{aligned}
& \mathrm{Ni}+2 \mathrm{O}_{2} \rightarrow \mathrm{Ni}^{2+}+2 \cdot \mathrm{O}_{2}^{-} \\
& \mathrm{O}_{2}^{-}+\mathrm{e}^{-}+2 \mathrm{H}^{+} \rightarrow \mathrm{H}_{2} \mathrm{O}_{2} \\
& \mathrm{Fe}^{2+}+\mathrm{H}_{2} \mathrm{O}_{2} \rightarrow \mathrm{Fe}^{3+}+\mathrm{OH}^{-}+\cdot \mathrm{OH}
\end{aligned}
$$

It has been demonstrated that loading catalysts on PEs can improve catalytic activity [7, 8]. Recently, it was shown that Pd-based catalysts hold great potential in 
direct synthesis of $\mathrm{H}_{2} \mathrm{O}_{2}$ from electro-generated $\mathrm{H}_{2}$ and $\mathrm{O}_{2}$ (Eqs. (4) - (6)), which greatly resolves the problems mentioned above $[9,10]$.

$$
\begin{aligned}
& 2 \mathrm{H}_{2} \mathrm{O}+2 \mathrm{e}^{-} \rightarrow \mathrm{H}_{2}+2 \mathrm{OH}^{-} \\
& 2 \mathrm{H}_{2} \mathrm{O} \rightarrow \mathrm{O}_{2}+4 \mathrm{H}^{+}+4 \mathrm{e}^{-} \\
& \mathrm{H}_{2}+\mathrm{O}_{2} \stackrel{\mathrm{Pd}}{\rightarrow} \mathrm{H}_{2} \mathrm{O}_{2}
\end{aligned}
$$

However, Pd has the drawbacks of possessing weak ability to catalyze $\mathrm{H}_{2} \mathrm{O}_{2}$ decomposition, being expensive, and difficult to recycle after treatment. Iron is a widely used Fenton catalyst since it is cost-effective, highly efficient and environmentally friendly [11]. Thus, modifying the noble metal such as Pd with iron to synthesize composite catalyst should be desirable. For instance, Qin et al [12] synthesized $\mathrm{AuPd} / \mathrm{Fe}_{3} \mathrm{O}_{4}$ nanoparticles as PEs, and their results showed that $\mathrm{AuPd} / \mathrm{Fe}_{3} \mathrm{O}_{4}$ nanoparticles electrodes possessed preferable electrochemical properties for in situ supplement of $\mathrm{H}_{2} \mathrm{O}_{2}$ and releasing of $\mathrm{Fe}^{2+}$, which activated Fenton-like reaction and thereby enhanced the degradation of pollutants. However, it should be noted that nanoparticles tend to aggregate, which would result in catalytic performance decline. Given this, supporting bimetallic Pd-Fe catalysts on support materials should be a more satisfied method.

In this study, we attempted to prepare novel Pd-Fe/Ni foam PEs, and use the as-synthesized PEs as effective multifunctional material in a $3 \mathrm{D}$ electrochemical reactor to combine the advantages of $3 \mathrm{D}$ reactor and Fenton-like reaction. Dimetridazole (DMZ) was chosen as the model compound for determining the electrocatalytic performance of the PEs. PEs characterizations were also performed. 


\section{Experimental}

2.1. Preparation and characterization of $\mathrm{Pd}-\mathrm{Fe} / \mathrm{Ni}$ foam

$\mathrm{Pd}-\mathrm{Fe} / \mathrm{Ni}$ foam PEs were prepared by impregnation-calcination method followed by reduction process as previously reported $[13,14]$. The PEs were characterized by FE-SEM, EDS, HRTEM, SAED, XRD, XPS, electrochemical impedance spectroscopy (EIS), linear scan voltammetry (LSV) and a surface area and pore size analyzer. The experiment details about preparations and characterizations of synthesized PEs are provided in supplementary materials.

\subsection{DMZ degradation experiments}

All experiments were performed in a 3D electrode reactor [15]. The anode and cathode were made of $\mathrm{Pt}$ sheets. $\mathrm{Na}_{2} \mathrm{SO}_{4}$ solution $(5 \mathrm{~g} / \mathrm{L})$ was used as the electrolyte. The concentration of DMZ solution was $50 \mathrm{mg} / \mathrm{L}$, and a total volume of $400 \mathrm{~mL}$ was fed into the $3 \mathrm{D}$ electrode reactor. The initial $\mathrm{pH}$ was adjusted with $0.5 \mathrm{~mol} / \mathrm{L} \mathrm{H}_{2} \mathrm{SO}_{4}$ or $\mathrm{NaOH}$ to 3. Compressed air with airflow of $1.0 \mathrm{~L} / \mathrm{min}$ was sparged into the system during the experiment. PEs dose was $12.5 \mathrm{~g} / \mathrm{L}$, and a current density of $31 \mathrm{~mA} / \mathrm{cm}^{2}$ was applied to the $3 \mathrm{D}$ system.

Electrolytic degradations of DMZ in 2D, 3D system (with Ni foam, Fe/Ni foam, $\mathrm{Pd} / \mathrm{Ni}$ foam and $\mathrm{Pd}-\mathrm{Fe} / \mathrm{Ni}$ foam as PEs, respectively) and two-compartment 3D system (separated by Nafion 117 membrane and with $\mathrm{Pd}-\mathrm{Fe} / \mathrm{Ni}$ foam as PEs) were performed under the same conditions in the same reactor. Pd-Fe/Ni foam PEs adsorption of DMZ was carried out in the electrochemical reactor without applied current. 


\section{Results and discussion}

\subsection{Characteristics of particle electrodes}

To demonstrate that bimetallic Pd-Fe catalysts have been successfully loaded on $\mathrm{Ni}$ foam, various characterizations were conducted. The raw $\mathrm{Ni}$ foam has a 3D network structure and the surface is relatively smooth (Fig.1a). For Fe/Ni foam, the surface is rough, and is coated with a "layer", consisting of some irregular shape particles, demonstrating that Fe species have been successfully deposited on Ni foam (Fig.1b). Pd-Fe/Ni foam possesses large silk-like flaky structures, resulting in larger specific surface area and more active sites for catalytic degradation, which is in favor of catalytic activity (Fig. 1c) $[16,17]$. Palladium and iron content of Pd-Fe/Ni foam are analyzed by EDS, and Pd and Fe amounts were $1.27 \mathrm{wt} \%$ and $12.84 \mathrm{wt} \%$ (Fig. S1), respectively. Fig. S2 shows EDS elemental mapping of $\mathrm{Pd}-\mathrm{Fe} / \mathrm{Ni}$ foam, which confirms that $\mathrm{Pd}, \mathrm{Fe}$ and $\mathrm{O}$ elements are highly dispersed in the $\mathrm{Pd}-\mathrm{Fe} / \mathrm{Ni}$ foam PEs.

To further investigate the crystallization behavior of Fe or Pd-Fe catalysts, these catalysts stripped from Ni foam were analyzed by HRTEM and SAED. In Fig. S3, clear lattice fringes with a lattice spacing of $0.256 \mathrm{~nm}$ can be observed. SAED patterns of Fe catalysts display several well-defined rings for the diffraction planes, suggesting good polycrystalline nature of Fe catalysts. The HRTEM image (Fig. S3) denotes a lattice spacing of $0.235 \mathrm{~nm}$, and Pd-Fe catalysts have good crystallinity with well-defined fringes.

The surface composition and metallic state of $\mathrm{Pd}$ and $\mathrm{Fe}$ of the $\mathrm{Pd}-\mathrm{Fe} / \mathrm{Ni}$ foam PEs were confirmed by XPS. As shown in Fig. S4, Ni, C, O, Fe, Pd elements can be 
found on Pd-Fe/Ni foam PEs. High-resolution XPS spectra of Pd $3 d$ and Fe $2 p$ are shown in Fig. S4. The binding energies of near 335.5 and $340.6 \mathrm{eV}$ belong to $\mathrm{Pd} 3 \mathrm{~d}_{5 / 2}$ and $\mathrm{Pd} 3 \mathrm{~d}_{3 / 2}$ peaks, which indicating that $\mathrm{Pd}$ species in $\mathrm{Pd}-\mathrm{Fe} / \mathrm{Ni}$ foam PEs are mainly metallic Pd. Except for $\mathrm{Pd}(0)$ species, another peak at $336.3 \mathrm{eV}$ was also found, which can be assigned to $\mathrm{Pd}^{2+}$ in $\mathrm{PdO}$. These results reflect the surface oxidation of $\mathrm{Pd}-\mathrm{Fe} / \mathrm{Ni}$ foam PEs due to exposure to air. The XPS spectra of Fe $2 p$ depicts two characteristic peaks at 724.5 and $710.5 \mathrm{eV}$, which can be assigned to $\mathrm{Fe} 2 \mathrm{p}_{1 / 2}$ and $\mathrm{Fe} 2 \mathrm{p}_{3 / 2}$, respectively. Two distinct bands centered at $710.3 \mathrm{eV}$ and $713.2 \mathrm{eV}$, whose values are close to the range of $\mathrm{Fe} 2 \mathrm{p}_{3 / 2}$ binding energies of iron in $\mathrm{FeO}$ and $\mathrm{Fe}_{2} \mathrm{O}_{3}$ [18], could be observed from the deconvolution of the XPS spectra of $\mathrm{Fe} 2 \mathrm{p}_{3 / 2}$, implying that the iron in our samples is present both as $\mathrm{Fe}^{2+}$ and $\mathrm{Fe}^{3+}$.

Fig. S5 shows the XRD patterns of $\mathrm{Ni}$ foam, $\mathrm{Fe} / \mathrm{Ni}$ foam and $\mathrm{Pd}-\mathrm{Fe} / \mathrm{Ni}$ foam. Notably, all the samples showed typical diffraction peaks at $44.5^{\circ}, 51.8^{\circ}$ and $76.2^{\circ}$,

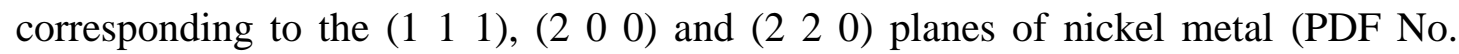
03-065-2865). No peaks for Pd and Fe were observed in Pd-Fe/Ni foam, which was likely due to lower amounts of $\mathrm{Pd}$ and Fe well-dispersed on the surface of $\mathrm{Pd}-\mathrm{Fe} / \mathrm{Ni}$ foam. Both EDS and XPS results discussed above confirmed that Pd and Fe were loaded on $\mathrm{Ni}$ foam. All the characterization results demonstrated that modified treatment of Ni foam PEs by bimetallic Pd-Fe catalysts have been successfully carried out.

\subsection{Electrochemical activities of particle electrodes}

The EIS was performed to examine the conductivity of PEs. Fig. 2 illustrates 
Nyquist plots for various PEs. The inset shows the enlarged view of high frequency region. Each impedance spectrum presents a semicircle arc at the high frequency range and a straight line at the low frequency region for all PEs. The diameter of semicircle in high frequency area represents the charge-transfer reaction at the electrode/electrolyte interface, and the other located at low frequency region where a straight sloping line represents the diffusion of ions in all the PEs [19]. The arc curvature at high frequency region of $\mathrm{Pd}-\mathrm{Fe} / \mathrm{Ni}$ foam PEs was smallest, indicating that $\mathrm{Pd}-\mathrm{Fe} / \mathrm{Ni}$ foam PEs exhibited the smallest charge transfer resistance. This is likely due to the fact that loadings of $\mathrm{Pd}$ and Fe species on Ni foam could decrease the resistance and accelerate the electron transfer on the $\mathrm{Pd}-\mathrm{Fe} / \mathrm{Ni}$ foam interface. This may be helpful for the Pd-Fe/Ni foam PEs to enhance the electrochemical degradation of pollutants and further reduce energy consumption.

LSV is a useful tool for evaluating the electrochemical activities of PEs. The true DMZ decomposition current was the current difference between the one with and without DMZ with various PEs (Fig. 3). The actual current density of degradation DMZ with different PEs followed the order of $\mathrm{Pd}-\mathrm{Fe} / \mathrm{Ni}$ foam $>\mathrm{Fe} / \mathrm{Ni}$ foam $>\mathrm{Ni}$ foam, implying that the Pd-Fe/Ni foam PEs had better electrochemical activity. This could be ascribed to the fact that the electronegativity of $\mathrm{Fe}(\mathrm{III})$ is 1.96 while that of $\operatorname{Pd}(0)$ is 2.20 , thus reduction of $\mathrm{Fe}(\mathrm{III})$ to $\mathrm{Fe}(\mathrm{II})$ by $\mathrm{Pd}(0)$ is favorable, behaving as Lewis acid sites, which is beneficial for the interfacial electron transfer and improving activities $[20,21]$.

3.3. DMZ degradation and $\mathrm{H}_{2} \mathrm{O}_{2}$ accumulation 
DMZ degradation results are shown in Fig. 4. For the adsorption experiment of Pd-Fe/Ni foam, only 4.2\% DMZ removal was obtained, which was insignificant for DMZ removal. The limited adsorption ability of $\mathrm{Pd}-\mathrm{Fe} / \mathrm{Ni}$ foam was because of its small BET surface area $\left(1.488 \mathrm{~m}^{2} / \mathrm{g}\right)$. When the $2 \mathrm{D}$ system was used, DMZ removal of $42.6 \%$ was attained. Meanwhile, using $\mathrm{Fe} / \mathrm{Ni}$ foam or $\mathrm{Pd} / \mathrm{Ni}$ foam in 3D systems, DMZ reduction of $78.1 \%$ and $63.0 \%$ were achieved, respectively, which reflected that $\mathrm{Pd} / \mathrm{Ni}$ foam had inerter catalytic activity compared with $\mathrm{Fe} / \mathrm{Ni}$ foam. A slightly improved DMZ removal efficiency of $82.3 \%$ was achieved in the two-compartment 3D system (with Pd-Fe/Ni foam as PEs). In a sharp contrast, almost 91.3\% of DMZ was removed within $30 \mathrm{~min}$ by 3D Pd-Fe/Ni foam system and DMZ removal reached $96.5 \%$ when the experiment was prolonged to $60 \mathrm{~min}$. This implied that the addition of Pd and Fe species greatly improved electrocatalytic performance of $\mathrm{Pd}-\mathrm{Fe} / \mathrm{Ni}$ foam PEs. This was supposed to be closely related to the in-situ catalysis decomposition of the generated $\mathrm{H}_{2} \mathrm{O}_{2}$ into $\cdot \mathrm{OH}$ during the process (discussed below), which could degrade DMZ more efficiently.

In the meantime, it was assumed that all the electrocatalytic degradation processes of DMZ followed pseudo-first order reaction kinetics. Time based rate constants $\left(\mathrm{min}^{-1}\right)$ were summarized in Table S1. In agreement with this degradation efficiency trend, the apparent rate constants of DMZ degradation in the whole 3D systems were higher than that in $2 \mathrm{D}$ system $\left(9.36 \times 10^{-3} \mathrm{~min}^{-1}\right)$. The rate constant $\left(0.0566 \mathrm{~min}^{-1}\right)$ of $3 \mathrm{D} \mathrm{Pd}-\mathrm{Fe} / \mathrm{Ni}$ foam system is much higher than that of $3 \mathrm{D} \mathrm{Fe} / \mathrm{Ni}$ foam system $\left(0.0255 \mathrm{~min}^{-1}\right)$ and 3D Pd/Ni foam system $\left(0.0155 \mathrm{~min}^{-1}\right)$, and even 
more than 1.36 times of their sum $\left(0.0411 \mathrm{~min}^{-1}\right)$. This significant enhancement of DMZ degradation suggested the existence of synergistic effect between $\mathrm{Pd}$ and $\mathrm{Fe}$ species in 3D Pd-Fe/Ni foam system. We have also investigated the Energy consumption $\left(\mathrm{E}_{\mathrm{EO}}\right)$ in these electrocatalytic systems (Table $\mathrm{S} 1$ ). $\mathrm{E}_{\mathrm{EO}}$ value for $3 \mathrm{D}$ $\mathrm{Pd}-\mathrm{Fe} / \mathrm{Ni}$ foam system was lower than other electrocatalytic systems. Thus 3D $\mathrm{Pd}-\mathrm{Fe} / \mathrm{Ni}$ foam system is more energy-saving and high efficient than the other processes.

Along with the degradation of DMZ, accumulations of $\mathrm{H}_{2} \mathrm{O}_{2}$ in different systems were determined. As shown in Fig. 5, negligible amount of $\mathrm{H}_{2} \mathrm{O}_{2}$ were detected for the cases of using $\mathrm{Pd}-\mathrm{Fe} / \mathrm{Ni}$ foam adsorption system and 2D system. In contrast, the concentration of $\mathrm{H}_{2} \mathrm{O}_{2}$ reached $61 \mu \mathrm{mol} / \mathrm{L}$ in $3 \mathrm{D} \mathrm{Ni}$ foam system; and the high accumulation of $\mathrm{H}_{2} \mathrm{O}_{2}$ in this system was because $\mathrm{Ni}$ foam could activate molecular oxygen to produce $\cdot \mathrm{O}_{2}{ }^{-}$and subsequently generate $\mathrm{H}_{2} \mathrm{O}_{2}$ (Eqs. (1)-(3)) [5]. Notably, the addition of $\mathrm{Pd}$ markedly elevated concentration of $\mathrm{H}_{2} \mathrm{O}_{2}$ for $\mathrm{Pd} / \mathrm{Ni}$ foam; the reason for this may be attributed to the fact that Pd species are favor for synthesis of $\mathrm{H}_{2} \mathrm{O}_{2}$, yet have weak ability to catalyze $\mathrm{H}_{2} \mathrm{O}_{2}$ decomposition. When Fe was loaded on the $\mathrm{Ni}$ foam, $\mathrm{H}_{2} \mathrm{O}_{2}$ accumulation decreased dramatically compared with the case of 3D Ni foam system. This could be contributed to quickly decomposition of $\mathrm{H}_{2} \mathrm{O}_{2}$ to generate more reactive oxygen species (ROS) in the presence of Fe. While inducing both $\mathrm{Pd}$ and $\mathrm{Fe}$ species, $\mathrm{H}_{2} \mathrm{O}_{2}$ accumulation declined significantly since Fe species can catalyze the decomposition of $\mathrm{H}_{2} \mathrm{O}_{2}$ to produce more active $\cdot \mathrm{OH}$, these were in line with DMZ degradations. Relatively low concentration of $\mathrm{H}_{2} \mathrm{O}_{2}$ was detected in 
3D Pd-Fe/Ni foam system, since the detected amount was residual $\mathrm{H}_{2} \mathrm{O}_{2}$, thus the equilibrium concentration of $\mathrm{H}_{2} \mathrm{O}_{2}$ was not high. To emphasize the role of $\mathrm{Pd}$ in $\mathrm{H}_{2} \mathrm{O}_{2}$ formation, which may follow reaction (6), accumulations of $\mathrm{H}_{2} \mathrm{O}_{2}$ in the two-compartment 3D system separated by Nafion117 membrane (with Pd-Fe/Ni foam as PEs) were performed to prevent the $\mathrm{H}_{2}$ formed on counter electrode get into the bulk electrolyte. The $\mathrm{H}_{2} \mathrm{O}_{2}$ concentration gradually increased to $7.62 \mu \mathrm{mol} / \mathrm{L}$ within the first $30 \mathrm{~min}$, and reduced afterwards, and was lower than those from 3D Pd-Fe/Ni foam systems. These results proved that $\mathrm{Pd}$ catalyst could in-situ synthesize $\mathrm{H}_{2} \mathrm{O}_{2}$ with the presence of $\mathrm{O}_{2}$ and $\mathrm{H}_{2}$ producing by water electrolysis, and $\mathrm{H}_{2} \mathrm{O}_{2}$ could be directly decomposed into $\cdot \mathrm{OH}$ by $\mathrm{Pd}$ catalyst (Eq.(7)), which promote decomposition of organic pollutants [9].

$$
\mathrm{H}_{2} \mathrm{O}_{2} \stackrel{\mathrm{Pd}}{\rightarrow} 2 \cdot \mathrm{OH}
$$

As a summary, Pd-Fe/Ni foam PEs are both particle electrodes of 3D reaction system and catalysts of Fenton-like reaction, leading to efficient electrochemical degradation of DMZ in the 3D electrode system, as shown in Fig. S6.

\subsection{Cyclic performance of $\mathrm{Pd}-\mathrm{Fe} / \mathrm{Ni}$ foam}

The stability of Pd-Fe/Ni foam PEs over eight consecutive cycles for the degradation of DMZ was evaluated. After each run, Pd-Fe/Ni foam PEs were recycled by filtration and washed with distilled water and then dried at $70{ }^{\circ} \mathrm{C}$ for 5 h. Fig. S7 reveals that removal efficiencies of DMZ could steadily maintain at more than $90 \%$ after eight consecutive cycles, demonstrating that $\mathrm{Pd}-\mathrm{Fe} / \mathrm{Ni}$ foam $\mathrm{PEs}$ have excellent electrocatalytic durability. It should be noted that the leaching iron ions were below 
$0.5 \mathrm{mg} / \mathrm{L}$ (for eight consecutive cycles are $0.47,0.42,0.36,0.30,0.33,0.27,0.22,0.18$ $\mathrm{mg} / \mathrm{L}$, respectively), which were acceptable according to EU discharge standards [22].

\section{Conclusions}

In summary, a three-dimensional electrode system with synthesized $\mathrm{Pd}-\mathrm{Fe} / \mathrm{Ni}$ foam PEs was used to degrade DMZ. The PEs displayed excellent performances for DMZ removal with low energy consumption by direct electrolytic, in-situ production of $\mathrm{H}_{2} \mathrm{O}_{2}$, Fenton-like catalytic reaction, and synergistic effects between $\mathrm{Pd}$ and $\mathrm{Fe}$ species were exhibited. The electrocatalytic durability of the $\mathrm{Pd}-\mathrm{Fe} / \mathrm{Ni}$ foam over eight cycles indicated an outstanding recycling capacity for long-term electrocatalytic reaction. This study provides a new point on preparing high performance catalysts loaded on particles to improve the performance of 3D electrode technology.

\section{Acknowledgments}

This work was financially supported by the National Science Foundation of China (No. 21367002). 


\section{References}

[1] Y.-s. Wang, F. Yang, Z.-h. Liu, L. Yuan, G. Li. Catal Commun. 67 (2015) 49-53.

[2] Neti, N. R, Misra, R. Chem. Eng. J. 184 (2012) 23-32.

[3] L. Yan, H. Ma, B. Wang, Y. Wang, Y. Chen. Desalination. 276 (2011) 397-402.

[4] G. Lv, D. Wu, R. Fu. J. Hazard. Mater. 165 (2009) 961-966.

[5] W. Liu, Z.H. Ai, L.Z. Zhang. J. Hazard. Mater. 243 (2012) 257-264.

[6] B.C. Tappan, S.A. Steiner, E.P. Luther, Angew. Chem.-Int. Edit. 49 (2010) 4544-4565.

[7] M. Li, F. Zhao, M. Sillanpää, Y. Meng, D. Yin, Sep. Purif. Technol. 156 (2015) 588-595.

[8] C. Zhang, L. Zhou, J. Yang, X. Yu, Y. Jiang, M. Zhou. Environ. Sci. Pollut. Res, 21 (2014) 8398-8405.

[9] S. Yuan, Y. Fan, Y. Zhang, M. Tong, P. Liao. Environ. Sci. Technol. 45 (2011) 8514-8520.

[10] M. Sun, G. Zhang, Y. Liu, H.J. Liu, J.H. Qu, J.H. Li. Chem. Eur. J. 21 (2015) 7611-7620.

[11] G. Pliego, J.A. Zazo, P. Garcia-Muñoz, M. Munoz, J.A. Casas, J.J. Rodriguez. Crit. Rev. Env. Sci. Tec. 45 (2015) 2611-2692.

[12] Y. Qin, M. Sun, H. Liu, J. Qu. Electrochimica Acta, 186 (2015) 328-336.

[13] M. Luo, S. Yuan, M. Tong, P. Liao, W. Xie, X. Xu. Water Res, 48 (2014) 190-199.

[14] M. Triki, S. Contreras, F. Medina. J Sol-Gel Sci Techn. 71 (2014) 96-101.

[15] Z.Y. Wang, J.Y. Qi, Y. Feng, K. Li, X. Li. Catal Commun, 46 (2014) 165-168.

[16] C.Sun, S.Ali Baig, Z.Lou. Appl. Catal. B Environ, 158-159 (2014) 38-47.

[17] Y.Ma, W. Chen, P. Zhang. RSC ADV, 4 (2014) 47609-47614.

[18] T. Zhang, J. Liu, D. Wang, Z. Zhao, Y. Wei, K. Cheng, G. Jiang. Appl. Catal. B Environ. 148-149 (2014) 520-531.

[19]L.S. Aravinda, K.K. Nagaraja, H.S. Nagaraja, K.U. Bhat, B.R. Bhat. Electrochimica Acta, 95 (2013) 119-124.

[20] X. Li, X. Liu, L. Xu, Y. Wen, J. Ma, Z. Wu. Appl. Catal. B Environ.165 (2015) 79-86.

[21] G. Chen, Y. Zhao, G. Fu, P.N. Duchesne, L. Gu, Y. Zheng, X. Weng, M. Chen, P. Zhang, C.-W. Pao, J.-F. Lee, N. Zheng. Science, 344 (2014) 495-499.

[22] W. He, Q. Ma, J. Wang, J. Yu, W. Bao, H. Ma, A. Amrane. Appl. Clay. Sci. 99 (2014) 178-186. 


\section{Figure captions}

Fig.1 (a) The SEM images of Ni foam; (b) Fe/Ni foam; (c) Pd-Fe/Ni foam.

Fig.2 EIS plots of Ni foam, Fe/Ni foam and Pd-Fe/Ni foam PEs (Inset: the enlarged view of the high frequency region).

Fig.3 LSV (scan rate $50 \mathrm{mV} / \mathrm{s}$ ) of $\mathrm{Ni}$ foam, Fe/Ni foam and Pd-Fe/Ni foam PEs in without DMZ solution and with $50 \mathrm{mg} / \mathrm{L}$ DMZ solution containing $5 \mathrm{~g} / \mathrm{L} \mathrm{Na} \mathrm{Na}_{2} \mathrm{SO}_{4}$ solution $(\mathrm{pH}=3)$.

Fig.4 The removal efficiency of DMZ in different systems.

Fig.5 The accumulation of the $\mathrm{H}_{2} \mathrm{O}_{2}$ in different systems. 
Figures
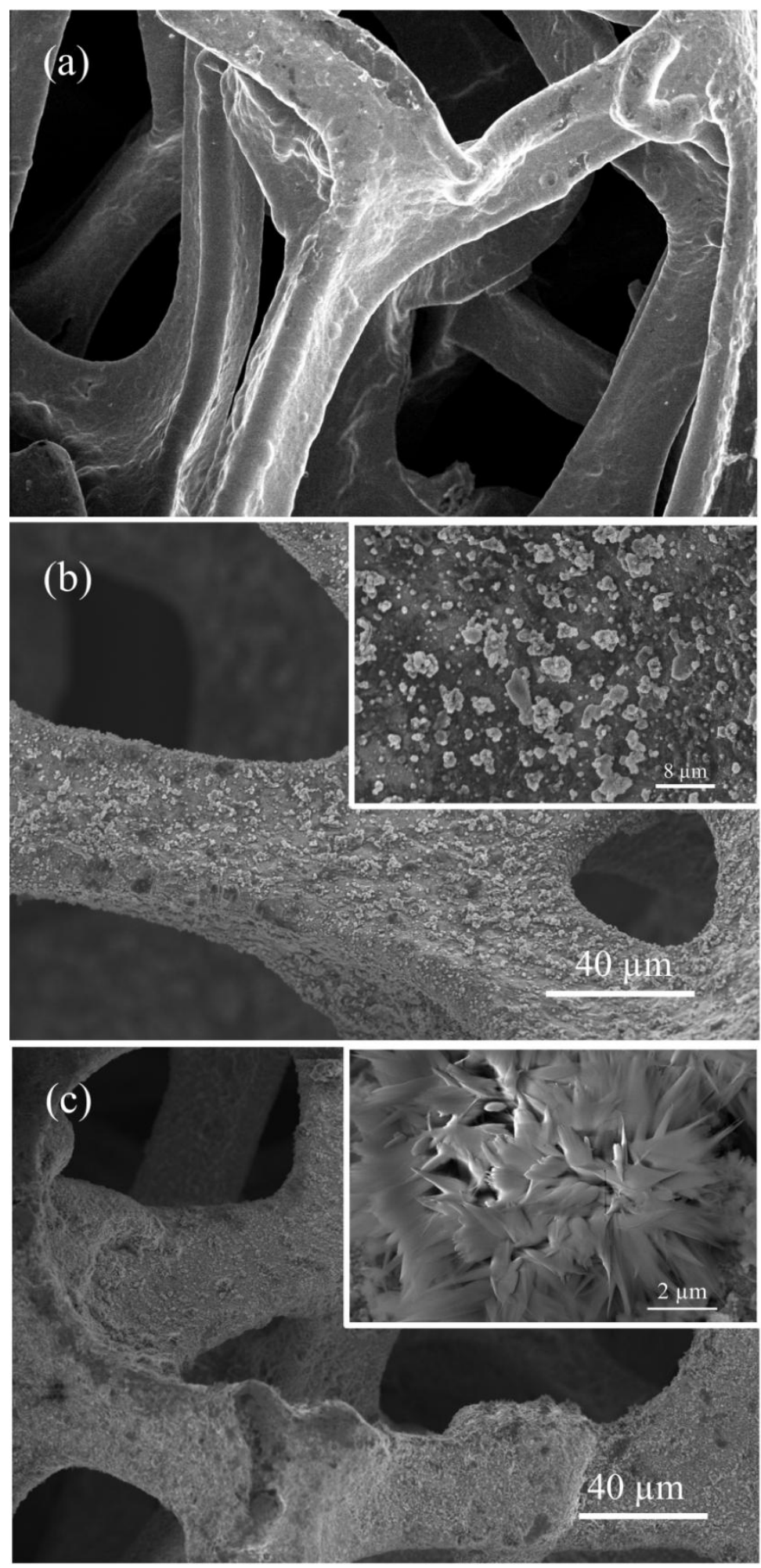

Fig. 1 


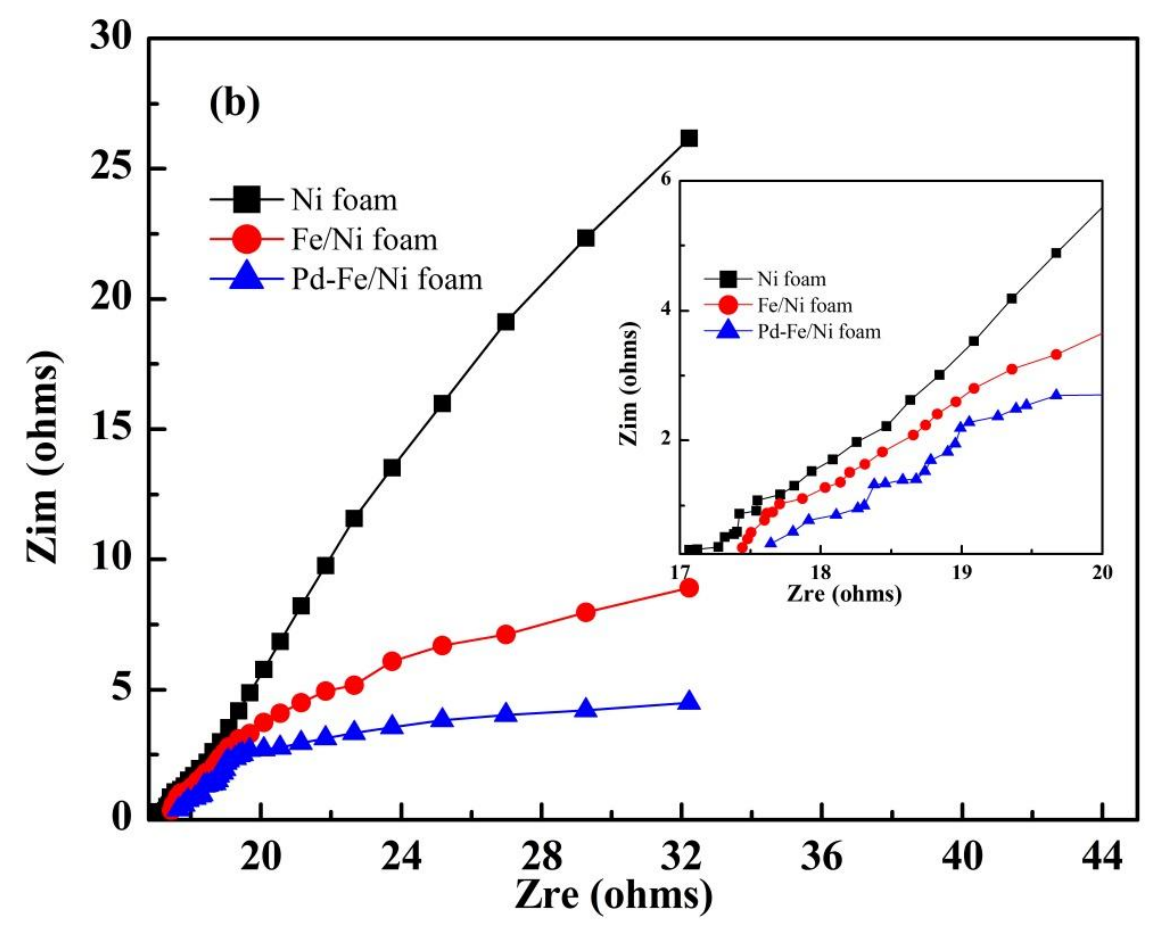

Fig. 2 


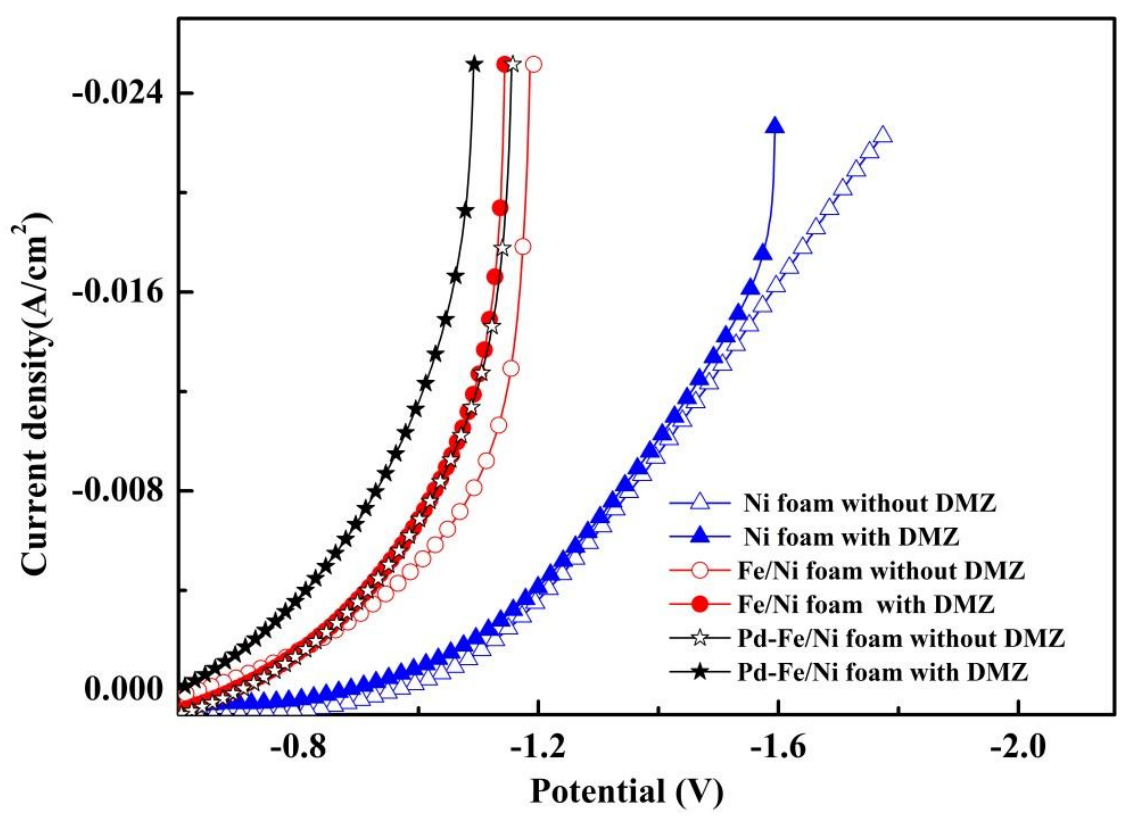

Fig. 3 


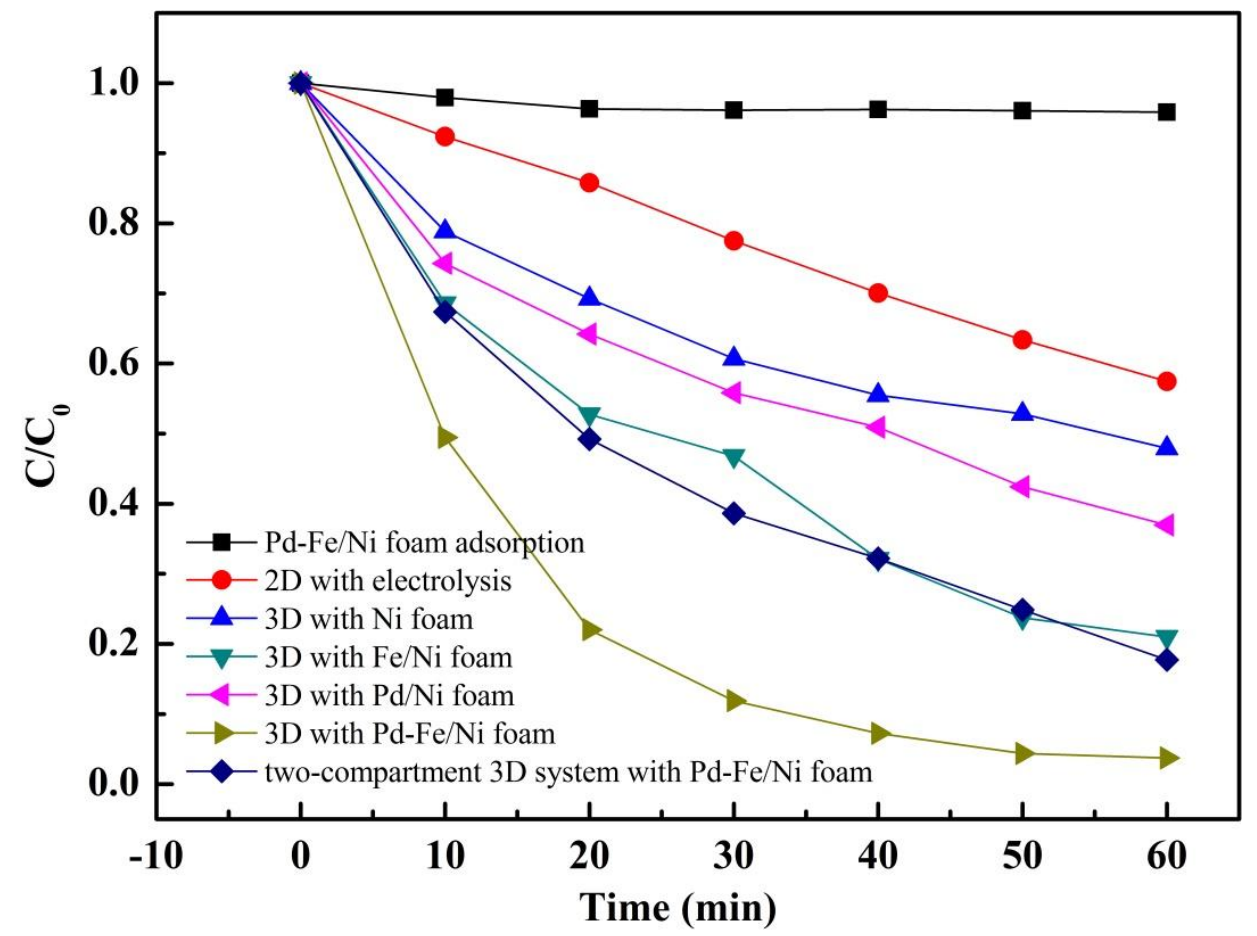

Fig. 4 


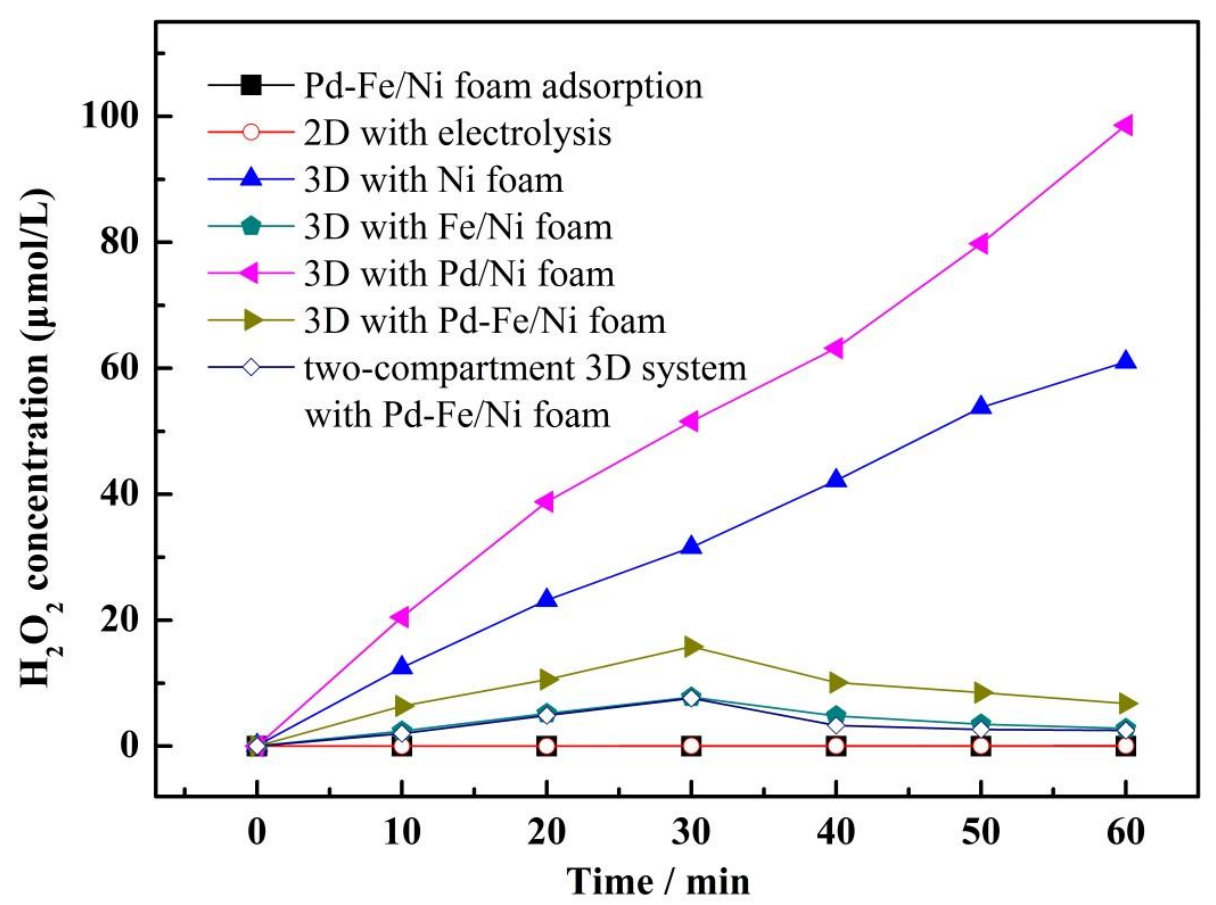

Fig. 5 


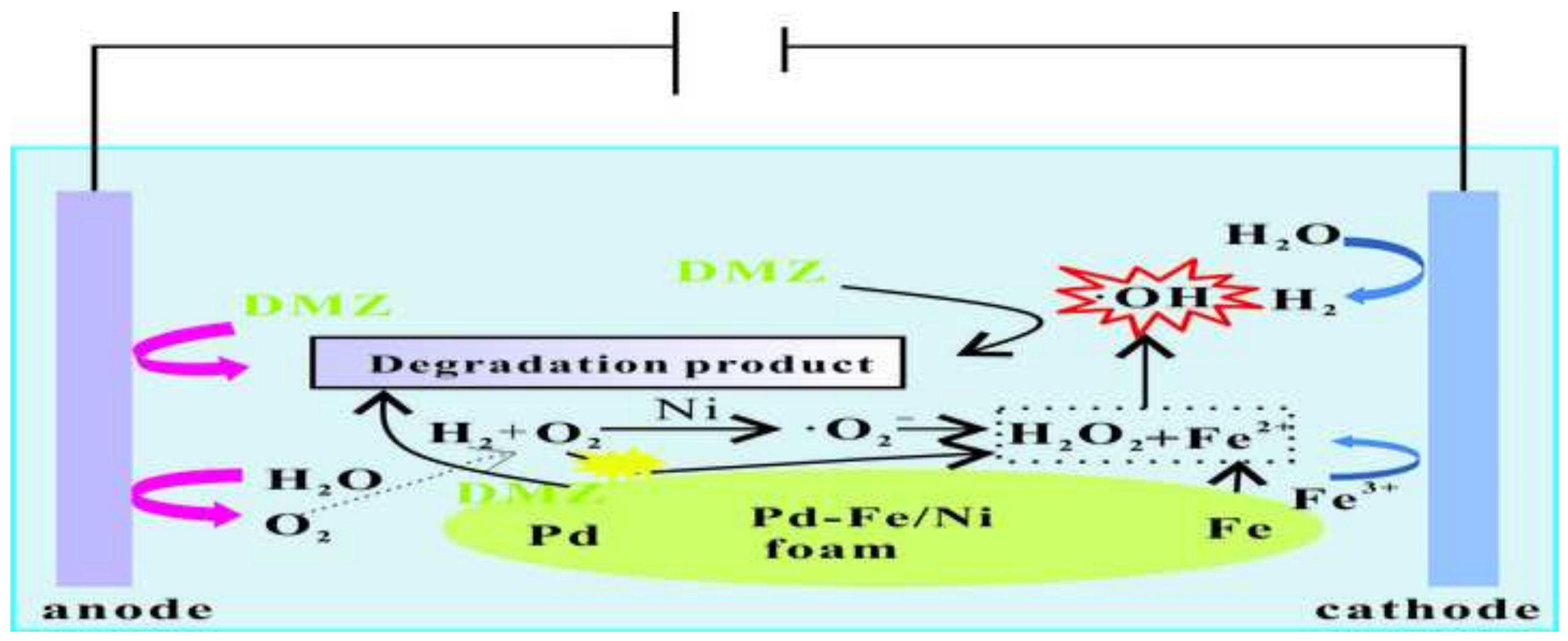

